\title{
Zero Mother Mortality Preeclampsia Program: Opportunity for a Rapid Acceleration in the Decline of Maternal Mortality Rate in Indonesia
}

\author{
Adhi Pribadi $^{*}$
}

\begin{abstract}
Objectives: Maternal mortality rate (MMR) in Indonesia was reported to be 305 per 100,000 live births. Preeclampsia is the first target to decrease because it is one of the preventable pregnancy complications. Currently, preeclampsia has patterns for treatment from early detection to delivery; therefore, reasonable chances of decreasing the MMR rapidly and significantly should be considered in Indonesia.

Materials and Methods: The reasons for choosing preeclampsia for reducing MMR included an early detection method, availability of affordable medication for the prevention of preeclampsia, development of a national guideline for medical practice regarding preeclampsia, establishment of health institutions by government and the private sector in remote areas, and availability of sufficient health personnel.

Results: Early detection of risk factors of preeclampsia is of great importance. Recommended preventive medication includes a combination of acetyl salicylic acid and calcium for 12 weeks for a high-risk group. National guidelines for the management of preeclampsia should be distributed to all hospitals including those covered by national health insurance.

Conclusions: The goal of zero mother mortality preeclampsia program is to make policies for all health workers and the general public so that the prevention process can take place. Delivery of all cases with hypertension should be performed in the hospital without exception so no delivery should be performed at home without specialist supervision.

Keywords: Maternal mortality, Preeclampsia, Prevention
\end{abstract}

\section{Introduction}

Maternal mortality is one of the targets (number 1) set by the World Health Organization (WHO) as a health indicator of a country (1). Based on the results of the Indonesian national survey, maternal mortality rate (MMR) in Indonesia has shown a decrease over time, but it is still relatively high compared to other Asian countries. MMR in Indonesia in 2015 was 305 per 100000 live births (2). Globally and in Indonesia, hypertension in pregnancy is the second most common cause of maternal deaths due to post-partum haemorrhage (PPH) (3).

National data in 2018 indicated that the population of Indonesia was 265015313 with 70715592 women of child-bearing age and 5291143 pregnant women (4). National data did not include information on the number of pregnant women with preeclampsia complications, but considering that preeclampsia occurs in $2 \%-8 \%$ (5) of pregnancies, preeclampsia patients may reach 105,822 to 423291 in a year. A total of 1232 preeclampsia cases were registered in 7 referral hospitals in Indonesia in 2016, and maternal mortality was reported to be about $2.2 \%$ despite treatment in tertiary referral centers (6). The total number of hospitals throughout Indonesia was 2269 in
2018 (4). Based on the mentioned data, it was estimated that maternal deaths in Indonesia due to preeclampsiaeclampsia may reach about 2328-9312 per year. This number can be reduced or eliminated by preventing preeclampsia or deaths from preeclampsia; therefore, the MMR can be reduced rapidly in Indonesia.

Minimal public awareness of the health of pregnant women becomes the determining factor of the death rate, although there are still many factors that must be considered to eliminate this problem, for example, empowerment of poor women, educational background, family, socioeconomic factors, community, and political policy. Men are also required to work actively on all issues of reproduction in a more responsible manner. Therefore, the view that considers pregnancy as a natural event needs to be changed socioculturally so that women can receive more attention from the community. It is very critical that efforts to improve care services come from the government, the private sector, and society, especially the husbands.

\section{Review of Literature}

The mode of delivering babies in Indonesia is dominated 
by midwives (the number of midwives was 217726 in 2018) with the highest number of delivery in the homes of pregnant women or at independent midwifery clinics (4). Traditional birth attendants still play a role during childbirth. Excessive bleeding is still the number one cause of maternal death probably due to difficulties of the cases and distance from health institutions. The policy of childbirth in health institutions is still far from being agreed upon because of various issues such as sociocultural, economic, and governmental policy. The effective reduction of maternal mortality due to bleeding is achieved by delivery in health institutions with adequate facilities and skills (not at home), where the delivery of babies is performed by trained personnel. It still takes time to send the mother to the hospital if there is excessive bleeding which can cause severe blood loss. In many cases, this is the cause of death among pregnant women due to blood loss in the transferring process.

Childbirth policies in health institutions have been adopted in several places. Although positive results are observed, there are still unpopular public policies which may not be adopted. In case of maintaining the current policy of allowing births at home, all midwives should be trained to handle bleeding. Unequal quality of education is another factor in upgrading the skills of midwives so that they can have comparable abilities to employ treatment for excessive bleeding. This is not possible because the number of midwives is so high and it is very costly for the government.

Four major causes of bleeding are tone, trauma, tissue, and thrombin (4), making $\mathrm{PPH}$ relatively difficult to handle by a midwife when delivering at home (3). Prevention of the $\mathrm{PPH}$ process is only achieved by administering oxytocin after the baby is born. Almost no early detection of $\mathrm{PPH}$ by midwives is possible in a remote area; however, fatalities can be avoided by a maximal preventive effort. The potential for $\mathrm{PPH}$ is only suspected from characterization of the patient, including pregnant women with the possibility of poor uterine contractions after delivery, especially in macrosomia, polyhydramnios, or multiple pregnancies. In contrast to $\mathrm{PPH}$, preeclampsia currently has patterns for treatment from early detection to delivery so reasonable chances of decreasing the MMR rapidly and significantly in Indonesia are achieved by decreasing the incidence of preeclampsia.

Preeclampsia is the first target because it is one of the preventable pregnancy complications and as health facilities and infrastructure are widespread in Indonesia, it can be addressed immediately. There have been many studies that explain that pre-eclampsia can be prevented by some medications and prevention, or altering one's lifestyle. Prevention with the provision of aspirin at low doses has been proven to be useful, so it should be used as a reference in the prevention of preeclampsia (7). Preventing the occurrence of preeclampsia may require a long period of time; therefore, realistic and probable goals in the near future are to prevent deaths from preeclampsia. However, a long-term goal is to prevent preeclampsia $(8,9)$.

The reasons for choosing preeclampsia as the first target for reducing MMR are as follows:

1. An early detection method can be developed based on 3 main aspects that can indicate the possibility of preeclampsia.

(a) Risk factors: High risk preeclampsia categories according to the American College of Obstetricians and Gynecologists (ACOG) if there are one or more of the following risk factors: Preeclampsia in previous pregnancy, multiple pregnancy, hypertension, diabetes mellitus, kidney illnesses, autoimmune diseases and obesity;

(b) Biophysical maternal parameters (blood pressure, arterial stiffness, and uterine arteries blood flow);

(c) Placental function: biochemical measurement parameters

2. Medication for the prevention of preeclampsiaeclampsia is relatively affordable.

The prevention of preeclampsia can be started by risk assessment and Doppler examination of the uterine artery from the first trimester. Furthermore, if there are risk factors, drugs can be administered for prevention. The recommended preventive medication is a combination of acetyl salicylic acid and calcium (inexpensive and easy to obtain). Calcium supplementation is associated with a significant reduction in the risk of preeclampsia. The provision of such supplements also reduces the role of premature birth. The WHO recommends $1.5 \mathrm{~g}$ to $2 \mathrm{~g}$ of calcium daily for areas with low dietary calcium intake. In settings with low calcium intake, a low-dose supplement option (500 to $600 \mathrm{mg} / \mathrm{d}$ ) may be considered $(10,11)$.

The use of low-dose aspirin from the first trimester of pregnancy in women at high risk of preeclampsia may reduce the incidence of pathologies. The aim of early diagnosis is to provide preventive therapy with 50-150 $\mathrm{mg}$ of acetylsalicylic acid (aspirin) before 16 weeks of pregnancy (12). The combination of aspirin and heparin for prevention seems to increase the success of efforts to prevent preeclampsia $(13,14)$.

The WHO guideline recommended a reference dose of $75 \mathrm{mg} / \mathrm{d}$ for aspirin before 20 weeks of gestation and, if possible, as early as 12 weeks of gestation (15). Meanwhile, ACOG supports recommendations on the use of $81 \mathrm{mg} / \mathrm{d}$ of aspirin starting from 12-16 weeks of gestation for highrisk preeclampsia (10).

3. There is a national guideline for medical practice regarding preeclampsia.

A national guide for medical practice regarding preeclampsia was issued by the Indonesian Society of Obstetrics and Gynecology (POGI) and the Ministry of Health. After the issuance of this guideline, it can be used as a reference to create a clinical, practical guide in all 
service settings throughout Indonesia. Guidance issued in the form of national guidelines will make it easier for health service providers to handle preeclampsia and hopefully the treatment will be uniform and clinically practical throughout Indonesia.

4. Health institutions were widely established by the government and the private sector in remote areas.

Until 2018, the number of general hospitals in Indonesia was recorded to be 2269. Based on the ownership, they include 1336 private general hospitals (58.9\%). The number of public primary health care centers was reported to be 9993 , with a ratio of 1:26520, and there were 8841 private clinics (4).

5. The number of health personnel is relatively sufficient. According to the data obtained from the Indonesian Association of Obstetrics and Gynecology in 2020, there are 3253 specialists (16) working in Indonesia and based on the data obtained from Indonesian Ministry of Health in 2018, a total of 56084 general practitioners work in remote areas, although they are not well dispersed (4).

\section{Discussion}

The steps of the program that can lead to zero maternal mortality due to preeclampsia are as follows:

\section{Early detection}

(a) Primary Services (Primary health care, clinics, general practitioners, midwives, other health workers)

- Detection of risk factors and prior risks during pregnancy including preeclampsia

- The cases with indications of high-risk factors may be referred to secondary health services for consultation and collaboration of management and may be returned to primary facilities for supervision by a specialist or handled directly at secondary facilities.

(b) Secondary and tertiary health services (district hospitals, national referral hospitals, obstetricians, pediatricians).

- Detection of high risk factors or complications (in principle, the same as primary care services)

- Consultation, collaboration with primary care for service centers in remote areas

- Management of complex complications tailored to existing facilities (depending on the type of hospital).

- Early detection using Doppler examination of the uterine artery for screening the high risk group.

2. Prevention

(a) Primary services

- Provision of calcium supplement $(1 \mathrm{~g} / \mathrm{d})$ in all pregnancies in settings with low calcium intake

- Low-dose aspirin (80 mg) for high-risk cases with physician supervision

(b) Secondary and tertiary services
- Administering calcium $(1 \mathrm{~g} / \mathrm{d})$ in all pregnancies in settings with low calcium intake

- Low-dose aspirin (80 mg) for high-risk cases with physician supervision

- Detection, stabilization, normalization, and prevention of pathological conditions that may aggravate pregnancy or predispose to preeclampsia before deciding to become pregnant.

3. Management of preeclampsia (referring to Indonesian guidelines for the management of preeclampsia in 2016)

(a) Primary services

- Provision of $\mathrm{MgSO} 4$ for cases with severe preeclampsia or eclampsia

- Referring the high-risk or predisposed cases of preeclampsia to secondary or tertiary services (early detection function)

- Not caring for patients with hypertension in pregnancy without consultation with obstetricians, gynecologists, and internal medicine specialists

(b) Secondary and tertiary services (subject to facilities)

- Provision of MgSO4 in all cases with severe preeclampsia or eclampsia

- Intensive care for postpartum mothers and babies

- Termination of pregnancy is considered for the following cases: Preeclampsia at $<26$ weeks; Uncontrolled preeclampsia; Severe preeclampsia at $\geq 34$ weeks; Preeclampsia with complications, e.g., HELLP, heart failure, pulmonary edema, kidney failure and so forth; eclampsia; fetal distress.

Steps of Activities

a. National guidelines for the management of preeclampsia should be distributed to all specialists of obstetrics and gynecology, midwives, and all health workers. This effort can be addressed in cooperation with other organizations such as the Indonesian medical doctors association, the midwives association, and local government.

b. Workshops should be held on Doppler examination of uterine arteries for early detection and prevention program (Cooperation with medical education center in all parts of Indonesia).

c. National guidelines for the management of preeclampsia should be distributed to all hospitals including those covered by national health insurance.

d. All pregnant women with high blood pressure are required to be hospitalized to prevent death caused by hypertension. This stage may require encouragement from the central or regional governments or making policy for that reason.

\section{Conclusions}

The goal of zero mother mortality preeclampsia program is to make policies for all health workers and the general public so that the prevention process can take place. In 
addition, delivery of all cases with hypertension should be performed in the hospital without exception. It is a regulation that all health workers and the general public must meet to prevent antenatal risk factors or hypertension in pregnancy care in primary services or delivery at home without specialist supervision.

\section{Conflict of Interests}

None.

\section{Ethical Issues}

Not applicable.

\section{Financial Support}

Partial financial support from Padjadjaran University.

\section{References}

1. WHO: Health Indicator. 2012. https://www.who.int/ healthinfo/EN_WHS2012_Part3.pdf.

2. BPS statistics Indonesia. 2015. https://www.bps.go.id/ publication/2016/11/30/63daa471092bb2cb7c1fada6/profilpenduduk-indonesia-hasil-supas-2015.html.

3. Edhi MM, Aslam HM, Naqvi Z, Hashmi H. Post partum hemorrhage: causes and management. BMC Res Notes. 2013;6:236. doi:10.1186/1756-0500-6-236

4. Indonesia Health Profile. 2018. https://pusdatin.kemkes.go.id/ resources/download/pusdatin/profil-kesehatan-indonesia/ Data-dan-Informasi_Profil-Kesehatan-Indonesia-2018.pdf.

5. Ghulmiyyah L, Sibai B. Maternal mortality from preeclampsia/ eclampsia. Semin Perinatol. 2012;36(1):56-59. doi:10.1053/j. semperi.2011.09.011

6. Aldika Akbar MI, Bachnas MA, Mose JC, et al. The massive problem of preeclampsia in Indonesia: in need of a redesigned national health care system. Pregnancy Hypertens. 2018;13 Suppl 1:S16. doi:10.1016/j.preghy.2018.08.051

7. Yu CK, Smith GC, Papageorghiou AT, Cacho AM, Nicolaides $\mathrm{KH}$. An integrated model for the prediction of preeclampsia using maternal factors and uterine artery Doppler velocimetry in unselected low-risk women. Am J Obstet Gynecol. 2005;193(2):429-436. doi:10.1016/j.ajog.2004.12.014

8. Sibai B, Dekker G, Kupferminc M. Pre-eclampsia Lancet. 2005;365(9461):785-799. doi:10.1016/s01406736(05)17987-2

9. Steegers EA, von Dadelszen P, Duvekot JJ, Pijnenborg R. Preeclampsia. Lancet. 2010;376(9741):631-644. doi:10.1016/ s0140-6736(10)60279-6

10. ACOG committee opinion No. 743: low-dose aspirin use during pregnancy. Obstet Gynecol. 2018;132(1):e44-e52. doi:10.1097/aog.0000000000002708

11. Rolnik DL, Wright $\mathrm{D}$, Poon LC, et al. Aspirin versus placebo in pregnancies at high risk for preterm preeclampsia. N Engl J Med. 2017;377(7):613-622. doi:10.1056/NEJMoa1704559

12. Duley L, Meher S, Hunter KE, Seidler AL, Askie LM. Antiplatelet agents for preventing pre-eclampsia and its complications. Cochrane Database Syst Rev. 2019;2019(10):CD004659. doi:10.1002/14651858.CD004659.pub3

13. Bujold E, Morency AM, Roberge S, LacasseY, Forest JC, Giguère Y. Acetylsalicylic acid for the prevention of preeclampsia and intra-uterine growth restriction in women with abnormal uterine artery Doppler: a systematic review and meta-analysis. J Obstet Gynaecol Can. 2009;31(9):818-826. doi:10.1016/ s1701-2163(16)34300-6

14. Gris JC, Chauleur C, Molinari N, et al. Addition of enoxaparin to aspirin for the secondary prevention of placental vascular complications in women with severe pre-eclampsia. The pilot randomised controlled NOH-PE trial. Thromb Haemost. 2011;106(6):1053-1061. doi:10.1160/th11-05-0340

15. de Vries Jl, van Pampus MG, Hague WM, Bezemer PD, Joosten JH. Low-molecular-weight heparin added to aspirin in the prevention of recurrent early-onset pre-eclampsia in women with inheritable thrombophilia: the FRUIT-RCT. J Thromb Haemost. 2012;10(1):64-72. doi:10.1111/j.15387836.2011.04553.x

16. Indonesian Association for Obstetrics and Gynecology. 2020. Available from: https://pogi.or.id/publish/\#.

(C) 2021 The Author(s); This is an open-access article distributed under the terms of the Creative Commons Attribution License (http:// creativecommons.org/licenses/by/4.0), which permits unrestricted use, distribution, and reproduction in any medium, provided the original work is properly cited. 